Review

\title{
Ferroptosis in Cardiovascular Diseases: Current Status, Challenges, and Future Perspectives
}

\author{
Yi Guo ${ }^{1,2,+}$, Chanjun $\mathrm{Lu}^{2,+}, \mathrm{Ke} \mathrm{Hu}^{2}$, Chuanqi Cai ${ }^{2}$ and Weici Wang ${ }^{2, *(\mathbb{C})}$ \\ 1 Clinic Center of Human Gene Research, Union Hospital, Tongji Medical College, Huazhong University of \\ Science and Technology, Wuhan 430022, China; hxshuyun@gmail.com \\ 2 Department of Vascular Surgery, Union Hospital, Tongji Medical College, Huazhong University of Science \\ and Technology, Wuhan 430022, China; m202075945@hust.edu.cn (C.L.); 2020508102@hust.edu.cn (K.H.); \\ chuanqicai@hust.edu.cn (C.C.) \\ * Correspondence: weiciwang@gmail.com; Tel.: +86-180-7170-5166 \\ + These authors contributed equally to this work.
}

check for updates

Citation: Guo, Y.; Lu, C.; Hu, K.; Cai,

C.; Wang, W. Ferroptosis in Cardiovascular Diseases: Current

Status, Challenges, and Future Perspectives. Biomolecules 2022, 12, 390. https://doi.org/10.3390/ biom12030390

Academic Editor: David E. Stec

Received: 27 January 2022

Accepted: 28 February 2022

Published: 2 March 2022

Publisher's Note: MDPI stays neutral with regard to jurisdictional claims in published maps and institutional affiliations.

Copyright: (C) 2022 by the authors. Licensee MDPI, Basel, Switzerland. This article is an open access article distributed under the terms and conditions of the Creative Commons Attribution (CC BY) license (https:// creativecommons.org/licenses/by/ $4.0 /)$.

\begin{abstract}
Cardiovascular diseases (CVDs) are still a major cause of global mortality and disability, seriously affecting people's lives. Due to the severity and complexity of these diseases, it is important to find new regulatory mechanisms to treat CVDs. Ferroptosis is a new kind of regulatory cell death currently being investigated. Increasing evidence showed that ferroptosis plays an important role in CVDs, such as in ischemia/reperfusion injury, heart failure, cardiomyopathy, and atherosclerosis. Protecting against CVDs by targeting ferroptosis is a promising approach; therefore, in this review, we summarized the latest regulatory mechanism of ferroptosis and the current studies related to each CVD, followed by critical perspectives on the ferroptotic treatment of CVDs and the future direction of this intriguing biology.
\end{abstract}

Keywords: ferroptosis; cardiovascular diseases; ischemia/reperfusion injury; heart failure; cardiomyopathy; atherosclerosis

\section{Introduction}

Ferroptosis, a new kind of cell death, originates from the Latin word "ferrum" and the Greek word "ptosis", meaning "iron" and "a fall", respectively [1]. Dixon and his colleagues first reported it in 2012 as an iron-dependent form of nonapoptotic cell death [2] It is characterized by dense, compact mitochondria with a loss of crista, which is unique and distinct from other forms of cell deaths, such as apoptosis (chromatin margination and condensation), necrosis (ruptured plasma membrane and swollen cytoplasm), and autophagy (enclosed double-membrane vesicles formation) [3,4]. Ferroptosis was determined to participate in many diseases such as tumors, neurodegenerative disorders (Alzheimer's disease, Parkinson's disease, Huntington's disease etc.), stroke, and ischemia/reperfusion $(\mathrm{I} / \mathrm{R})$, and it became a hotspot and focus of research, meriting further exploration.

Cardiovascular diseases (CVDs), a major cause of global mortality and disability, greatly affect people's lives [5]. One ongoing multinational collaboration study shows that the burden of CVDs was increasing in nearly all countries [6]. The age-standardized rate of CVDs is even increasing in some high-income countries that previously had a declining rate [7]. Recent research demonstrated that ferroptosis participates in several CVDs, such as I/R [8-11], heart failure (HF) [12,13], cardiomyopathy [14,15], and atherosclerosis [16]. Given the huge potential of ferroptosis in the treatment of CVDs, the latest work should be summarized, together with a report on the progress of possible medical usage.

In this review, we present the latest regulatory mechanism of ferroptosis and current studies related to each CVD, followed by critical perspectives on present challenges on the ferroptotic treatment of CVDs and the prospects of this intriguing biology. 


\section{The Regulating Pathways of Ferroptosis}

Ferroptosis was first proposed by Dixon as an iron-dependent regulated cell death [17]. Triggered by small specific molecules such as erastin, a small RAS gene selective molecule, and RAS-selective lethal 3 (RSL3), ferroptosis is characterized by the unique morphological changes of mitochondria. The overproduction of lipid peroxides, not clearing in time, increases membrane permeability, reduces fluidity, and destroys ionic homeostasis; thus, affecting the normal structure and function of membrane, ultimately leading to cell death [18]. Iron metabolism is critical in the formation of lipid peroxides [19]. Xc-GSH-GPX4 pathway [20], FSP1-CoQ10-NAD(P)H pathway [21,22], GCH1-BH4-DHFR pathway [23,24], and mitochondria [25] all play an important role in scavenging excess lipid peroxides and regulating the process of ferroptosis (Figure 1).

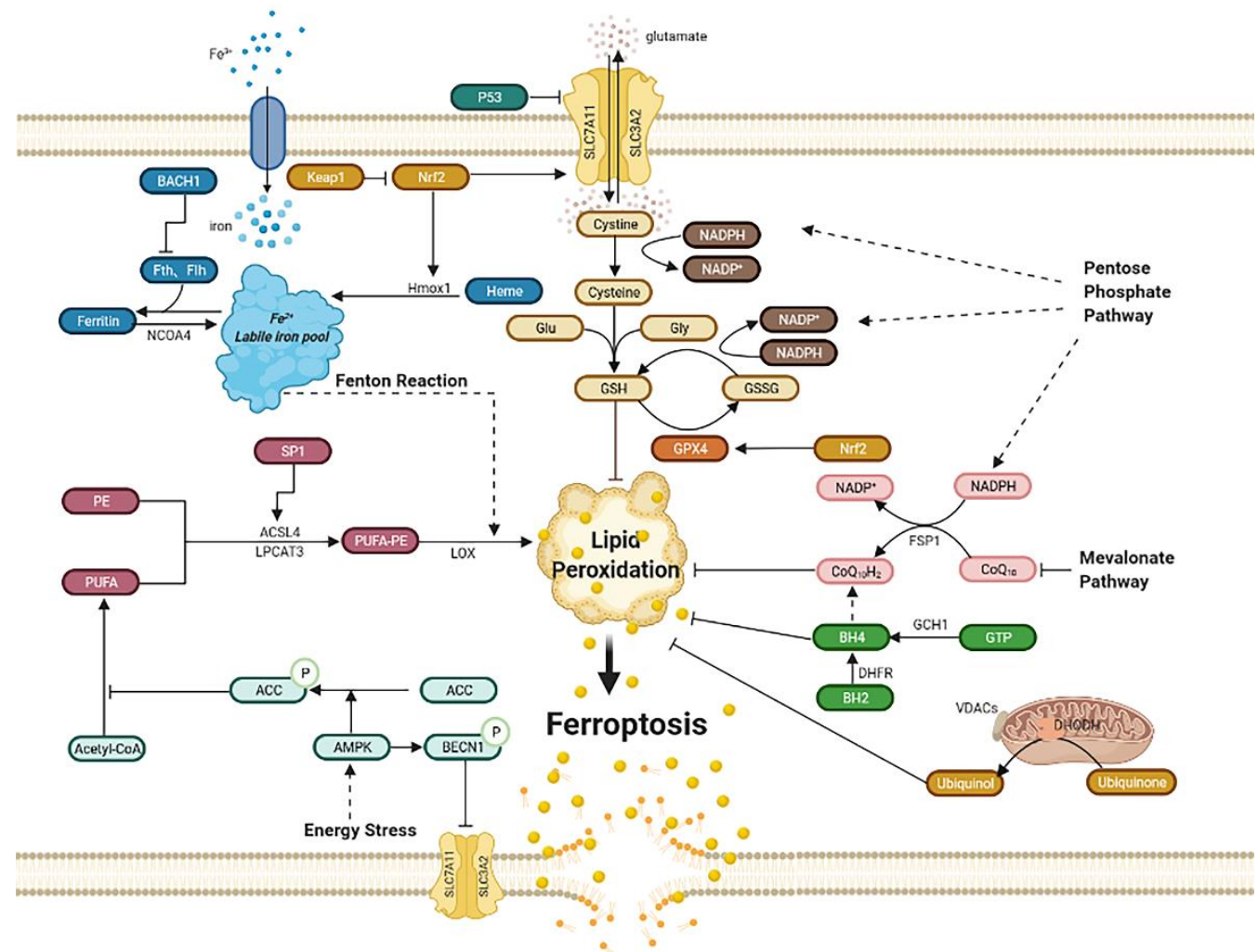

Figure 1. Regulatory pathways of ferroptosis. Ferroptosis is an iron-dependent, new kind of cell death. Regulatory pathways are complex, which can mainly be divided into several parts: iron metabolism; lipid peroxidation; Xc-GSH-GPX4 pathway; FSP1-CoQ10-NAD(P)H pathway; GCH1-BH4-DHFR pathway. Mitochondria and energy stress also play an important role. Abbreviations: BACH1: BTB domain and CNC homolog 1; Fth1: ferritin heavy chain 1; Ftl1: ferritin light chain 1; NCOA4: nuclear receptor coactivator 4; Hmox1: heme oxygenase-1; Keap1: Kelch-like ECH associated protein 1; Nrf2: nuclear factor erythroid 2-related factor 2; PE: phosphatidyl ethanolamine; PUFA: poly-unsaturated fatty acid; PUFA-PE: poly-unsaturated fatty acid-phosphatidyl ethanolamine; Sp1: special protein 1; ACSL4: acyl-CoA synthetase long-chain family member 4; LPCAT3: lysophosphatidylcholine acyltransferase 3; LOX: lipoxygenase; ACC: acetyl-CoA carboxylase; AMPK: AMP-activated protein kinase; BECN1: beclin 1; SLC7A11: subunit solute carrier family 7 member 11; SLC3A2: solute carrier family 3 member 2; Glu: glutamate; Gly: glycine; GSH: glutathione; GSSG: oxidized glutathione; GPX4: glutathione peroxidase 4; GCH1: guanosine triphosphate cyclohydrolase 1; GTP: guanosine triphosphate; $\mathrm{BH} 4$ : tetrahydrobiopterin; $\mathrm{BH} 2$ : dihydrobiopterin; DHFR: dihydrofolate reductase; DHODH: dihydroorotate dehydrogenase; VDACs: voltage-dependent anion channels; FSP1: ferroptosis suppressor protein1. 


\subsection{Iron Metabolism}

Iron overload can lead to ferroptosis. Iron, the most abundant trace element in vivo, is regulated to maintain appropriate levels. Apart from being part of the composition of the human body, iron can be detrimental due to its active redox capacity, such as Fenton and Fenton-like reactions, which means ferrous iron $(\mathrm{Fe} 2+)$ can react with oxygen or hydrogen peroxide $\left(\mathrm{H}_{2} \mathrm{O}_{2}\right)$ and produce plenty of hydroxyl radicals and lipid peroxides, thus ultimately leading to ferroptosis [19]; therefore, regulating iron homeostasis is of great importance. Iron homeostasis is related to nuclear receptor coactivator 4 (NCOA4)-mediated ferritinophagy, a kind of autophagy that turns ferritin into intracellular iron [26-29]. Heme oxygenase-1 (Hmox1) also contributes to iron homeostasis, which exerts the degradation of heme and produces ferrous iron [30,31]. The activation of ferritinophagy or overexpression of Hmox1can increases the free iron level, leading to lipid peroxides accumulation and ultimately ferroptosis. In addition, BTB domain and CNC homolog 1 (BACH1), a transcription factor, can promote ferroptosis by downregulating ferritin genes, including ferritin heavy chain 1 (Fth1) and ferritin light chain 1 (Ftl1), which reduce the amount of free labile iron. Therefore, it is possible to inhibit BACH1 to reduce free labile iron and further alleviate ferroptosis [32].

\subsection{Lipid Peroxidation}

Ferroptosis can be induced by lipid peroxidation, consisting of nonenzymatic lipid peroxidation like Fenton reaction and enzymatic lipid peroxidation mediated by the activity of the lipoxygenase (LOX) family. Poly-unsaturated fatty acid-phosphatidyl ethanolamine (PUFA-PE) can be metabolized by Fe2+ and LOX to produce lipid peroxides. Polyunsaturated fatty acid (PUFA), especially arachidonic acid (AA) and adrenaline, can be catalyzed by acyl-CoA synthetase long-chain family member 4 (ACSL4) and lysophosphatidylcholine acyltransferase 3 (LPCAT3), and they then take part in the biosynthesis of PUFA-PE with phosphatidylethanolamine (PE). Once the generation of lipid peroxides is hyperactive, lasting depletion of PUFA affects the normal structure and function of membrane and eventually leads to cell death [19]. ACSL4 is identified as a pivotal biomarker of ferroptosis. Knocking down ACSL4 by shRNA inhibits ferroptosis, whereas the overexpression of ASCL4 contributes to the sensitivity of ferroptosis by modulating the cellular lipid composition [33]. Special protein 1 (Sp1), an important factor, activates ACSL4 transcription when binding to the promoter region of ACSL4 [34]; consequently, increasing the expression or catalytic activity of ASCL4, LPCAT3, LOX, or Fenton reaction leads to lipid peroxides accumulation and, ultimately, ferroptosis [35].

\subsection{Xc-GSH-GPX4 Pathway}

The Xc-GSH-GPX4 pathway is the main pathway to regulate ferroptosis. Ferroptosis is mainly induced by a large number of reactive oxygen species (ROS), far beyond the capability of clearing mechanisms. The main clearing mechanism that reduces ROS is the redox ability of glutathione (GSH). GSH, a tripeptide that includes glutamic acid, cysteine, and glycine, acts as an antioxidant and is the substrate of glutathione peroxidase 4 (GPX4), which is then converted into oxidized glutathione (GSSG). Increasing the expression of GSH can inhibit ferroptosis. Furthermore, the System $\mathrm{X}_{\mathrm{c}-}$, composed of subunit solute carrier family 7 member 11 (SLC7A11) and solute carrier family 3 member 2 (SLC3A2), mediates the exchange of cystine and glutamate across the plasma membrane at the ratio of 1:1 to synthesize GSH. The inhibition of System $\mathrm{Xc}_{\mathrm{c}}-$ by erastin can lead to ferroptosis due to GSH depletion. This inhibition may cause the complete opposite effect of inhibiting ferroptosis. Inhibiting SLC7A11 decreases the amount of cystine and causes NADPH "debt" to reduce cystine to cysteine, thus impairing antioxidant ability and driving cells to ferroptosis [36]. As for GPX4, it is a kind of selenoenzyme that reduces ROS through GSH [20]. The inhibition of GPX4 by RSL3 leads to an impairment of antioxidant capacity, and then to ferroptosis. 
Moreover, P53 can also regulate ferroptosis in two diametrically opposed ways [37]. On the one hand, some studies report that P53 can lower the expression of SLC7A11, which affects the cystine transport function of system $\mathrm{Xc}_{\mathrm{c}}$ and further inhibits the activity of GPX4, ultimately leading to ferroptosis [38]. On the other hand, P53 is reported to inhibit ferroptosis in some cells, involving cyclin-dependent kinase inhibitor 1 A (CDKN1A), a p53 transcriptional target [39].

Furthermore, nuclear factor erythroid 2-related factor 2 (Nrf2) increases the level of SLC7A11 and transcriptionally induces the expression of GPX4, which then reduces ROS; therefore, the overexpression of Nrf2 can inhibit ferroptosis, whereas the Kelch-like ECH associated protein 1 (Keap1), bonding to Nrf2 and negatively regulating it, can reverse this process and exert a proferroptosis role [40,41]. However, Nrf2 can also induce ferroptosis by upregulating Hmox1 then degrading heme and releasing free iron, which ultimately leads to ferroptosis [14].

Cystine starvation can lead to ferroptosis because cysteine is crucial to GSH synthesis as a rate-limiting substrate, and the followed glutamate accumulation increases ROS. Interestingly, in nonsmall-cell lung cancer (NSCLC) cells, cystine starvation inducing ferroptosis can be inhibited by the generation of $\gamma$-glutamyl-peptide for reducing glutamate stress, which is catalyzed by glutamate-cysteine ligase catalytic subunit (GCLC), a Nrf2 regulating protein [42]. In high-fat diet-induced nonalcoholic fatty liver disease (NAFLD), ferroptosis contributes its development, and ginkgolide B (GB) is effective for treatment by inhibiting lipid accumulation and oxidative stress, which are probably related to Nrf2 elevation induced by GB [43]. All these show that Nrf2 is a crucial target regarding ferroptosis.

\subsection{FSP1-CoQ10-NAD(P)H Pathway}

Ferroptosis suppressor protein 1 (FSP1), previously named apoptosis-inducing factor mitochondria-associated 2 (AIFM2), is thought to inhibit ferroptosis as an independent system that co-operates with the Xc-GSH-GPX4 pathway [21,22]. That means FSP1 is capable to eliminate lethal lipid peroxides even in the absence of GPX4. Acting as an oxidoreductase, FSP1 reduces ubiquinone (also named coenzyme Q10) into ubiquinol by NADPH, another antioxidant compound besides GSH, which can inhibit ferroptosis by lessening lipid ROS. Moreover, inhibiting the mevalonate pathway may decrease the amount of coenzyme Q10, thus leading to ferroptosis [44] However, a study also showed that ubiquinol production is not essential for ferroptosis resistance mediated by FSP1, while endosomal sorting complexes required for transport III(ESCRT-III)-dependent membrane repair is responsible for it [45]. Anyway, they all elaborate that FSP1 is a potential target for ferroptosis-related diseases.

\subsection{Mitochondria}

The dramatic morphological features of ferroptosis are the dense, compact mitochondria with the loss of crista. It is unique and distinct from other forms of cell death, such as apoptosis (chromatin margination and condensation), necrosis (ruptured plasma membrane and swollen cytoplasmic), and autophagy (enclosed double-membrane vesicles formation) [46]. Voltage-dependent anion channels (VDACs), the ample protein located in the outer mitochondrial membrane, are essential to ferroptosis as a potential erastin target. The more VDACs proteins cells exist, the more sensitivity these cells exhibit to ferroptosis [47]. Moreover, the mechanism of mitochondria participating in ferroptosis involves cystine starvation and glutaminolysis, which raise the content of membrane potential (MMP) and ferrous iron content and contribute to Fenton reaction and lipid peroxidation, leading to ferroptosis [48,49].

Dihydroorotate dehydrogenase (DHODH), found on the inner membrane of mitochondrial, is reported to generate ubiquinol from ubiquinone by modulating the transformation of dihydroorotate to orotate, which demonstrates as a parallel way from mitochondrial GPX4 to protect cells from lipid peroxidation. Moreover, GPX4 knocks down sensitizing 
human tumor cells to DHODH inhibition. DHODH inhibitor maybe the potent anticancer agent in low GPX4 expression cancer. This mechanism of DHODH in mitochondrial is similar to the FSP1 system in cytosolic. Overexpression of FSP1 on mitochondria cannot affect lipid peroxidation, suggesting that the ferroptosis regulating the function of FSP1 may require some proteins on the plasma membrane [25].

\subsection{GCH1-BH4-DHFR Pathway}

The guanosine triphosphate cyclohydrolase 1 (GCH1)-tetrahydrobiopterin (BH4)dihydrofolate reductase (DHFR) pathway is another regulatory mechanism independently from Xc-GSH-GPX4 axis. Under the induction of ferroptosis by RSL3, erastin, and Gpx4 knockout, GCH1 exerts strong protective effect, which is selective from other forms of cell death [23]. The upregulation of GCH1 increases the content of BH4, an endogenous antioxidant, which captures lipid-derived peroxyl radicals to block the process of lipid peroxidation. Moreover, DHFR is the most efficient way for the regeneration of BH4 [24]; therefore, GCH1-BH4-DHFR pathway inhibits ferroptosis by subverting lipid peroxidation.

\subsection{Energy Stress}

Energy stress is one of metabolic stress, characterized by the increase in intracellular AMP and the consumption of intracellular ATP. Adenosine monophosphate (AMP)-activated protein kinase (AMPK) is crucial to energy stress by stimulating the ATP-producing catabolic processes and inhibits ATP-consuming anabolic processes [50]. Activation of AMPK in energy stress increases phosphorylation of acetyl-CoA carboxylase (ACC), thus hindering the synthesis and oxidation of fatty acids, which illustrates how energy stress inhibits ferroptosis [51]. A study also reports that AMPK promotes ferroptosis by phosphorylating BECN1 (beclin 1), binding to SLC7A11, then inhibiting cystine transport [52]; therefore, the precise effect of energy stress or AMPK needs further investigation.

\section{Ferroptosis in Different Cardiovascular Cells}

\subsection{Endothelial Cells}

It is suggested that erastin can induce ferroptosis in human umbilical vein endothelial cells (HUVECs), and the overexpression of miRNA17-92 can greatly alleviate it through A20 (known as tumor necrosis factor alpha-induced protein 3, TNFAIP3)-ACSL4 axis [1].When exposed to PM2.5, endothelial cells are injured due to ferroptosis because of increased iron content and lipid overoxidation [2]. In addition, overloaded iron induces ferroptosis and apoptosis to promote the calcification of endothelium, which can be alleviated by the application of ferroptosis inhibitors and iron chelators [53]. One study showed that high systemic iron levels can lead to the activation and dysfunction of the endothelium, which ultimately promote atherosclerosis formation [54]. Ferroptosis inhibitors like ferrostatin1 and deferoxamine mesylate can partially rescue this kind of endothelial lesion [2]. In subarachnoid hemorrhage (SAH) model, treating endothelial cells with cepharanthine (CEP) exhibits less 15-lipoxygenase-1 (ALOX15) level and less typical ferroptotic morphological changes in mitochondria [55]. Reported to promote vascular regeneration and improve endothelial function, Astragaloside IV is helpful to protect endothelial cells from ferroptosis by inhibiting lysophosphatidylcholine (LPC)-induced ROS in HUVECs, which can be largely reversed by ferroptosis agonist. All these studies suggest that ferroptosis is a promising target to protect endothelium [56].

\subsection{Vascular Smooth Muscle Cells}

Interestingly, one study shows that cigarette smoke extract (CSE) can induce ferroptosis by increasing lipid peroxidation and decreasing intracellular GSH in A7r5 cells and primary rat vascular smooth muscle cells (VSMCs), which can be completely inhibited by ferrostatin-1, liproxstatin-1, and deferoxamine-the specific ferroptosis inhibitors. Acrolein and methyl vinyl ketone in CSE were determined to be the main causes [3]. Treating VSMCs with palmitic acid (PA) upregulates the expression of extracellular matrix protein 
periostin (POSTN), which inhibits SLC7A11 expression by suppresses the expression of P53 gene in VSMCs, and therefore reduces the synthesis of GSH, leading to ferroptosis. However, pretreating with metformin activates Nrf2 pathway, a powerful antioxidant system, significantly reducing ferroptosis in VSMCs [57]. All of these indicate that we can target ferroptosis to protect VSMCs.

\subsection{Macrophages}

As for ferroptosis in macrophages, one study shows that iron load, which is a contributor to ferroptosis, can trigger the macrophage's polarization toward a proinflammatory phenotype, M1 [58]. M1 macrophages, with strong expression of inducible nitric oxide


sitive to it; therefore, iNOS/NO• has antiferroptosis effects and is the reason why M1 macrophages can exist with great viability under excess iron [4]. Macrophage migration inhibitory factor (MIF), overexpressed in nasopharyngeal carcinoma (NPC) cells, significantly inhibits ferroptosis in macrophages, which is conducive to NPC metastasis [59]. Treating macrophage with LPS to generate sepsis models in vitro, it is shown that both 4-octyl itaconate (4-OI) and ferrostatin-1 significantly upregulate the expression of GPX4, SLC7A11C, and Nrf2, exhibiting a protective effect for THP-1 macrophage and inhibiting lipid peroxidation induced by LPS. Further, this ferroptosis resistance is highly dependent on Nrf2 [60].

\subsection{Cardiomyocytes}

Ferroptosis-related cardiomyocyte death was reported in several cardiovascular diseases. Owing to the stimuli of an abundance of free radicals, cardiomyocytes suffer from ferroptosis and cannot be regenerated; therefore, it is crucial to inhibit ferroptosis, which can maintain the structure and function of the heart [8].

Ferroptosis is related to doxorubicin (DOX)-induced cardiotoxicity through upregulating Hmox1, which can release iron by degrading heme in cardiomyocytes, leading to plenty of cardiotoxic reactive oxygen species (ROS) [15]. Moreover, diabetes creates a high risk of cardiovascular disease, and that inhibition of ferroptosis can reduce cardiomyocyte injury in high glucose models, which relates to endoplasmic reticulum stress (ERS) aggravation [9,61]. It was demonstrated that the mechanistic target of rapamycin (mTOR) is protective in cardiomyocytes treated with ferric citrate, erastin, or RSL3, which can all induce ferroptosis. The protective role of mTOR is due to the reduction in excess iron and suppression of ROS [62]. One study reported that overexpressing Slc7a11 and treatment with Fer-1 can protect against ferroptosis in cardiomyocytes [63]. A recent study shows that the expression of USP22 protein, a kind of deubiquitinase, can inhibit ferroptotic cardiomyocyte death through the SIRT1/p53/SLC7A11 axis and further protect against myocardial ischemia/reperfusion injury [64].

In the ongoing COVID-19 epidemic, one case report shows that ferroptosis signature, immunohistochemical staining with E06, which reflects lipid peroxidation, is positive in COVID-19 myocardium and is negative in unknown-etiology viral myocarditis. The result may indicate that COVID-19 myocardium is related to ferroptosis, which merits further exploration [65].

\section{Ferroptosis in Cardiovascular Diseases}

\subsection{Ferroptosis in Ischemia/Reperfusion (I/R)}

Inhibiting ferroptosis can reduce $I / R$ injury. $I / R$ and ferroptosis were studied in several organs, such as the heart [8-11,29], kidney [51,66-68], brain [69], intestine [8], and liver [70] (Table 1). I/R includes two parts: ischemia and reperfusion. Ischemia means the sudden block of blood supply in an aerobic organ, and reperfusion means the restoration of blood supply. These processes lead to excessive production of ROS and free radicals, which result in the inflammatory cascade, cell injury, and ferroptosis [71]. 
Table 1. Target ferroptosis to reduce I/R injury in different organs.

\begin{tabular}{|c|c|c|c|c|c|}
\hline Organs & Models and Cells & Compounds & Targets & $\begin{array}{l}\text { Mechanisms and } \\
\text { Consequences }\end{array}$ & References \\
\hline heart & $\begin{array}{l}\text { Sprague-Dawley } \\
\text { rats, H9c2 cell }\end{array}$ & Fer-1 & ACSL4; GPX4 & $\begin{array}{l}\text { ACSL4 reduced; GPX4 increased; } \\
\text { infarct size reduced. }\end{array}$ & [9] \\
\hline heart & Mice (C57BL/6J) & Fer-1 & AA & $\begin{array}{l}\text { 5-HETE, 11-HETE, 12-HETE, and } \\
\text { 15-HETE reduced; infarct size } \\
\text { reduced; left ventricular improved. }\end{array}$ & [8] \\
\hline heart & Mice (C57BL/6J) & Lip-1 & GPX4; ROS & $\begin{array}{l}\text { GPX4 increased; ROS decreased; } \\
\text { infarct size reduced; mitochondrial } \\
\text { structural integrity and function } \\
\text { maintained. }\end{array}$ & [10] \\
\hline renal & HK-2 cells & ALR & GPX4; ROS & $\begin{array}{l}\text { ROS decreased; ALR and GPX4 } \\
\text { colocalized; renal I/R injury } \\
\text { protected. }\end{array}$ & [67] \\
\hline renal & Mice & 2DG; AICAR; Fer-1 & AMPK; PUFA & $\begin{array}{l}\text { AMPK activation; renal I/R injury } \\
\text { protected. }\end{array}$ & {$[51]$} \\
\hline renal & $\begin{array}{l}\text { Mice }(\mathrm{C} 57 \mathrm{BL} / 6) \\
\text { HK-2 cells }\end{array}$ & $\begin{array}{l}\text { Panx1 } \\
\text { deletion }\end{array}$ & $\begin{array}{l}\text { Hmox1, } \\
\text { NCOA4, } \\
\text { Fth1 }\end{array}$ & $\begin{array}{l}\text { Hmox1 upregulated, NCOA4 and } \\
\text { FTH1 inhibited; lipid peroxidation } \\
\text { decreased; renal I/R injury } \\
\text { protected. }\end{array}$ & [66] \\
\hline renal & Mice (C57BL/6) & Fer-1 & & renal I/R injury protected. & [72] \\
\hline intestine & $\begin{array}{l}\text { Mice }(\mathrm{C} 57 \mathrm{BL} / 6) \\
\text { Caco-2 cells }\end{array}$ & Lip-1; ROSI & GPX4 ACSL4 & $\begin{array}{l}\text { GPX4 induced; ACSL4 inhibited; } \\
\text { intestine I/R injury protected. }\end{array}$ & {$[34]$} \\
\hline brain & $\begin{array}{l}\text { Mice }(\mathrm{C} 57 \mathrm{BL} / 6) \\
\text { PC12 cells }\end{array}$ & $\begin{array}{l}\text { LV-shRNA-PVT1 } \\
\text { or LV-miR-214 }\end{array}$ & GPX4, SLC7A11 & $\begin{array}{l}\text { GPX4 and SLC7A11 increased; } \\
\text { infarct size reduced. }\end{array}$ & [69] \\
\hline brain & Mice (C57BL/6) & Lip-1; Fer-1 & & infarct size reduced. & [73] \\
\hline brain & $\begin{array}{l}\text { Mice }(\mathrm{Sv} 129 / \mathrm{J}) \\
\text { purified cortical } \\
\text { neurons. }\end{array}$ & Desferrioxamine & HIF-1 & $\begin{array}{l}\text { HIF-1 increased; tolerance against } \\
\text { reversible focal cerebral ischemia. }\end{array}$ & [74] \\
\hline liver & Mice (C57BL/6) & Lip-1 & & liver I/R injury reduced. & [70] \\
\hline
\end{tabular}

ROS are central to I/R. Inhibiting ERS, triggered by ROS, can alleviate ferroptosis in diabetes myocardial I/R injury [9]. Compared with nondiabetic hearts, the expression of GPX4 decreases while malondialdehyde (MDA) and 4-hydroxynonenal (4-HNE) increases during myocardial I/R injury in diabetic rats. NADPH oxidase (Nox), the main donor of ROS, is responsible for the oxidative stress in diabetic rat hearts, which is closely related to AMPK [75]. It is reported that the inhibition of glutaminolysis reduces the amount of ROS and increases GSH, thus inhibiting ferroptosis in heart I/R injury [76]. Augmenter of liver regeneration (ALR), colocalized with GPX4, possesses the ability to inhibit ferroptosis by decreasing ROS [67].

Other pathways elucidate the role of ferroptosis in I/R. Liproxstatin-1 (Lip-1), a ferroptosis inhibitor, protects heart I/ $\mathrm{R}$ injury by reducing voltage-dependent anion channel 1 (VDAC1) levels and increasing GPX4 levels [10,11]. Iron homeostasis is also important because a cohort study shows that the ability to rapidly process iron will be impaired during kidney I/R, which leads to ferroptosis in the end [68].

Ferroptosis can also promote the neutrophil's adhesion to coronary vascular endothelial cells by Toll-like receptors 4 (TLR4)/TIR domain-containing adapter inducing IFN-beta (Trif)/type I IFN signaling pathway, which aggravates inflammation and leads to I/R injury [8]. Additionally, overexpression of miR-214 or silencing plasmacytoma variant 1 (PVT1) could significantly inhibit ferroptosis and reduce brain infarct size in mice [69]. Renal I/R injury can be attenuated by pannexin 1 (PANX1) depletion for a decrease in 
mitogen-activated protein kinase (MAPK)/extracellular signal-regulated kinase (ERK) activation, which inhibits ferroptosis [66].

\subsection{Ferroptosis in Heart Failure}

The development of heart failure is related to the loss of myocytes and is proven to have a relationship with ferroptosis. In an integrated bioinformatical analysis, Tolllike receptors 4 (TLR4) and NADPH oxidase4 (NOX4) were increased in HF. Knocking down TLR4 and NOX4 can remarkably inhibit myocyte death mediated by ferroptosis [12]. Another mechanism revealing the role of ferroptosis in HF is mixed lineage kinase 3 (MLK3). MLK3 induces ferroptosis by regulating JUN/p53 mediated oxidative stress in chronic HF. miR-351 can inhibit this kind of heart failure by suppressing the expression of MLK3 [77]. Iron is critical to ferroptosis, the homeostasis of which also plays an important role in HF. Disrupting the ferritin heavy chain (Fth) gene in mice leads to HF owing to iron deposition, whereas decreasing cardiac iron in mice by lacking transferrin receptor 1 (Tfr1) also leads to HF $[78,79]$. Furthermore, people suffering from HF also have decreased Tfr1 and cardiac iron [63].

There are several compounds to treat HF by regulating ferroptosis. Injecting TLR4siRNA or NOX4-siRNA lentivirus can protect the failing heart via inhibiting ferroptosis. Puerarin, an antioxidant, can inhibit lipid oxidation and iron overload in mice with heart failure induced by isoprenaline [13]. Deferoxamine, a ferroptosis inhibitor, was reported to mitigate HF or cardiac infarction [15]. All the above suggests that ferroptosis might be a promising target for HF.

\subsection{Ferroptosis in Cardiomyopathies}

\subsubsection{Anticancer Drug-Induced Cardiomyopathy}

Doxorubicin (DOX), a generally used anticancer drug, exerts severe side-effects, such as heart failure and cardiomyopathy. An RNA-sequencing result has shown that the expression of the heme oxygenase- 1 (Hmox 1 ) gene is significantly higher in mouse hearts treated with DOX than that of the control, which means Hmox1 is critical for DOX-induced cardiomyopathy [15]. Moreover, the role of Hmox1 is related to ferroptosis. Nrf2 can upregulate Hmox1 to degrade heme and release free irons, thus inducing ferroptosis in cardiomyocytes [14]. Although excess iron is hazardous, selectively cardiomyocyte Fth deficient mice also suffer mild cardiomyopathy, and dietary iron cannot rescue it but instead leads to severe heart injury through ferroptosis [63]; therefore, iron homeostasis is critical to cardiomyopathy related to ferroptosis. Furthermore, knocking down P53 can increase the expression of SLC7A11 to inhibit ferroptosis and administering Fer-1 is protective for DOX-treated animals [80,81]. Dexrazoxane (DXZ), one iron chelator, is an FDA-approved compound treating DOX-induced cardiomyopathy through inhibit ferroptosis. Mito-TEMPO, targeting mitochondria, the main organelle to produce DOX-Fe2+ induced lipid peroxide, suppresses DOX-related ferroptosis, and protects cardiomyocytes similar to Fer-1 [15,82].

\subsubsection{Diabetic Cardiomyopathy}

Diabetes mellitus, closely related to heart structure and function damage, can lead to cardiomyopathy via ROS's overproduction and reduction in antioxidant ability, which is an important promoting factor of ferroptosis. NRF2, inhibiting ferroptosis by modulating antioxidant expression to reduce lipid ROS, is a promising target for diabetic cardiomyopathy (DCM) [83,84]. Hydrogen sulfide (H2S) can increase glutathione to synthesize GSH in DCM, which reduces lipid peroxidation and further inhibits ferroptosis [85]. Consequently, ferroptosis is likely to play a role in DCM.

This section may be divided by subheadings. It should provide a concise and precise description of the experimental results, their interpretation, as well as the experimental conclusions that can be drawn. 


\subsubsection{Iron Overload-Induced Cardiomyopathy}

Iron overload (IO)-induced cardiomyopathy is thought to have a relationship with ferroptosis, which includes a high level of lipid oxidation and iron overload and usually occurs in hereditary hemochromatosis and diseases needing frequent blood transfusions such as thalassemia [86-88]. Treating cardiomyocytes with $80 \mu \mathrm{g} / \mathrm{mL}$ ferric ammonium citrate for $72 \mathrm{~h}$ promotes eicosanoids production and arachidonic acid release, which increases lipid peroxides and affects cardiomyocyte rhythmicity, suggesting a causal link between these signals and electromechanical abnormalities in IO-induced cardiomyopathy [89]. Mitochondrial Ca uniporter (mCU), which mediates iron uptake, is important to IO-induced cardiomyopathy. Compared to those of $\mathrm{mCU}+/+(\mathrm{WT})$ mice, $\mathrm{mCU}-/-(\mathrm{KO})$ have lower mitochondrial iron and ROS levels and better systolic function; therefore, ferroptosis participates in IO-induced cardiomyopathy. Administering ferrostatin-1 protects heart function also confirms this point of view [90].

\subsection{Ferroptosis in Atherosclerosis}

Atherosclerosis is mainly caused by lipid deposition, endothelial cell damage, the proliferation of VSMC, and transformation of macrophages, and so on [54]. All these processes involve ferroptosis. Lipid deposition, especially PUFAs, is the substrate of the LOX or Fenton reaction, leading to oxidized lipids and inducing ferroptosis. In highfat diet (HFD)-fed Apo E-/-mice, the administering of Fer-1, a ferroptosis inhibitor, can promote the expressions of SLC7A11 and GPX4, partially inhibit the iron accumulation and lipid peroxidation, as well as increase ox-LDL-induced mouse aortic endothelial cells (MAECs) viability [16]. Moreover, endothelial cells can be damaged by lipid ROS, increasing the endothelial permeability, promoting lipid deposition, and initiating atherosclerosis. In HUVECs, miRNA17-92 overexpression greatly alleviates erastin-induced cell death through the A20-ACSL4 axis [1]. That means inhibiting ferroptosis in endothelial cells can alleviate endothelial damage and reduce the probability of atherosclerosis. Studies showed that the iron level in healthy arterial tissue is less than that in atherosclerotic plaque [91]. Iron overload is also a key point to induce ferroptosis; therefore, restricting iron, especially nontransferrin bound iron (NTBI), a deleterious iron form, is thought to be therapeutic for atherosclerosis by inhibiting ferroptosis [54,92]. Furthermore, iron overload even changes macrophage function, leading it to polarize toward the proinflammatory subtype [58]. This chronic inflammation of the macrophage contributes to the formation of atherosclerotic necrotic core and destabilization of plaque [93]; therefore, ferroptosis can induce atherosclerosis via iron overload and macrophage changes.

\subsection{Ferroptosis in Aging}

Ferroptosis is related to aging because of the role of iron and excess ROS. Iron accumulates with aging as the need for iron decreases as the metabolic rate reduces, and the amount of hemoglobin also decreases with aging [94]. One experiment on rabbits shows that, compared to that of young ones, aged rabbits possess more free iron, released from ferritin, and this leads to further oxidative damage, which may be related to ferroptosis, because the ferroptosis inhibitor, deferoxamine, is protective of this kind of damage [95].

\subsection{Ferroptosis in Vascular or Ventricular Remodeling}

The homeostasis of iron is critical to ferroptosis and the pathogenesis of vascular and ventricular remodeling. One study shows that iron deficiency contributes to vascular remodeling in the pulmonary of rat [96]. On the contrary, another study reports that restricting iron may moderately alleviate hypoxia-induced vascular remodeling in the pulmonary of mice [97]. As for the heart, it is believed that the myocardial iron in the infarct zone is adverse for ventricular remodeling [98]; therefore, the role of iron and ferroptosis in vascular remodeling needs more investigation (Figure 2). 


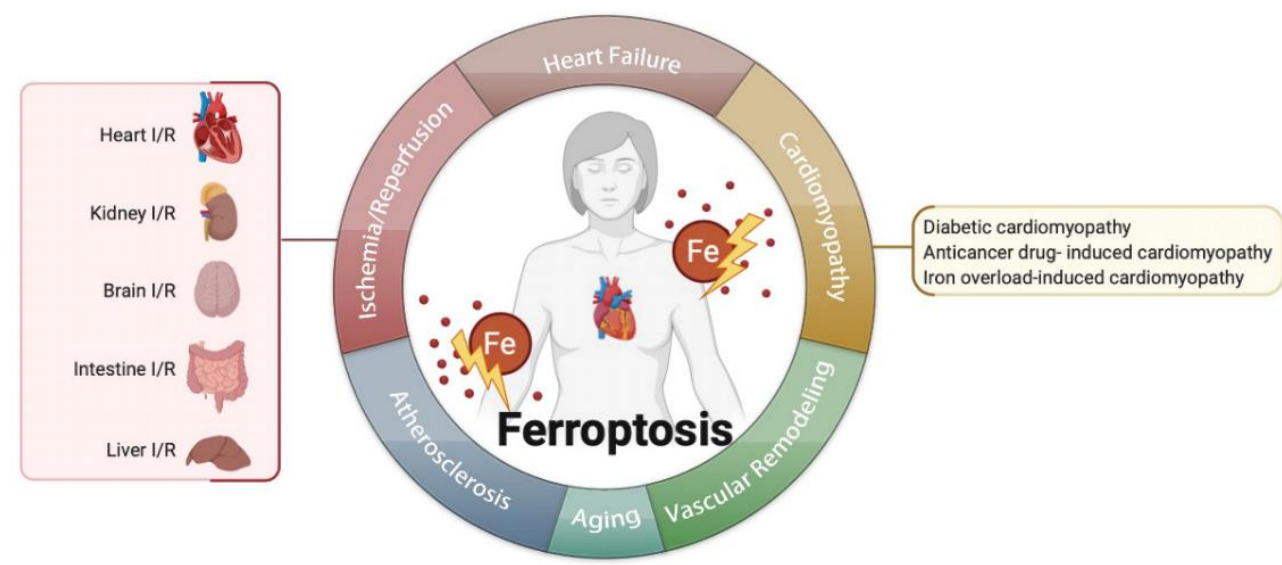

Figure 2. Ferroptosis is related to multiple cardiovascular diseases, such as ischemia/reperfusion, heart failure, cardiomyopathies, atherosclerosis, aging, vascular remodeling, and so on.

\section{Pharmacologic Modulation of Ferroptosis in Cardiovascular Diseases}

Several compounds could modulate ferroptosis; however, most of them are just applied in the experiment to test whether they are effective for cardiovascular disorders (Table 2). Of note, ferroptosis inhibitors seem to be dose-dependent. One study report that treating mice with either inhibitor at a lower dose $\left(5 \mathrm{mg} \mathrm{kg}^{-1}\right.$ compared with $\left.10 \mathrm{mg} \mathrm{kg}^{-1}\right)$ is also helpful but cannot reach the same extent [73]. Consequently, it is required to determine the appropriate dose for treatment.

Table 2. Pharmacologic compounds modulating ferroptosis in cardiovascular diseases.

\begin{tabular}{|c|c|c|c|c|}
\hline Mechanisms & Compound & Model & Effects & References \\
\hline \multirow[t]{7}{*}{ reduce iron overload } & deferoxamine & mice & mitigate HF or cardiac infarction. & [15] \\
\hline & nanochelators & mice & $\begin{array}{l}\text { the same as deferoxamine but have less } \\
\text { side-effect and rapid renal excretion. }\end{array}$ & [99] \\
\hline & $\begin{array}{l}\text { desferrioxamine } \\
\text { mesylate }\end{array}$ & human & improve left ventricular ejection fraction & [100] \\
\hline & deferiprone & human & improve left ventricular ejection fraction & [100] \\
\hline & deferasirox & human & improve left ventricular ejection fraction & [100] \\
\hline & DXZ & mice & $\begin{array}{l}\text { treating DOX-induced cardiomyopathy through } \\
\text { inhibit ferroptosis }\end{array}$ & [15] \\
\hline & rapamycin & mice & $\begin{array}{l}\text { target mTOR to protect ferroptotic } \\
\text { cardiomyocytes }\end{array}$ & {$[62]$} \\
\hline \multirow[t]{7}{*}{ reduce lipid ROS } & Fer-1 & mice & protect ferroptotic cardiomyocytes damage & [63] \\
\hline & Fer-1 & mice & promote the expressions of SLC7A11 and GPX4 & [16] \\
\hline & Fer-1 & mice & alleviate DOX-induced cardiomyopathy & [80] \\
\hline & Lip-1 & mice & $\begin{array}{l}\text { protect heart I/R injury by reducing VDAC1 } \\
\text { levels and increasing GPX4 levels. }\end{array}$ & [10] \\
\hline & vitamin $\mathrm{E}$ & mice & protect ferroptotic cell damage & [101] \\
\hline & zileuton & mice & $\begin{array}{l}\text { protect neurodegenerative disease by inhibiting } \\
\text { 5-Lipoxygenase }\end{array}$ & [102] \\
\hline & Mito-TEMPO & mice & suppress DOX related ferroptosis and protect & [15] \\
\hline
\end{tabular}

\section{Challenges at Present}

Ferroptosis, an iron-dependent cell death, is reported to participate in the formation and regulation of cardiovascular diseases. Given that the causes and treatments of CVDs 
are complex, and ferroptosis can be a potential target for treatments, we can combine the pharmacologic modulation targeting of ferroptosis with the existing treatment to cope with the drug resistance.

Although the treatment is promising, most of the drugs are all limited to experimental stages. Furthermore, the treatment extent varies with the ferroptosis inhibitor dose, and the exact dose is uncertain. Moreover, because most of the CVDs are chronic, ferroptosis inhibitors should be applied for a long time. Besides, the drug distribution is not target-specific but all over the body, which may lead to several side effects. For example, deferoxamine, an iron chelator, is reported to be ototoxic and neurotoxicity [103]; therefore, safer and more effective formulations deserve more exploration.

There is also hidden trouble with ferroptosis inhibitors. It was demonstrated that ferroptotic inducers effectively inhibit cancers in many studies; therefore, when we use ferroptosis inhibitors for cardiovascular disease therapy, this may lead to carcinogenesis, which is a potential risk.

Interestingly, contradictory to our previous view that upregulating SLC7A11 is antiferroptotic, the expression of SLC7A11 was recently reported to have the opposite effect because the amount of cystine increased and led to a crisis of NADPH "debt" when reducing cystine to cysteine, which can impair the antioxidant ability and drive cells to ferroptosis [36].

Moreover, the role of energy stress in ferroptosis also creates controversy. Energy stress induces AMPK activation, leading to ACC inactivation and the decrease in PUFA and other fatty acids [51]; however, a study also reports that AMPK promotes ferroptosis by phosphorylating BECN1. Phosphorylated BECN1 can be bind to SLC7A11, then inhibits cystine transport [52].

Consequently, on account of the controversies we state above, more investigation is required to comprehensively decipher and detail the mechanism when targeting SLC7A11 and AMPK as treatments for CVDs.

\section{Future Perspectives}

Ferroptosis was demonstrated to be significant in cancer and thought to be a promising avenue for cancer therapy. Several clinical drugs were already proved to induce ferroptosis in tumor cells, such as sorafenib [104,105], sulfasalazine, salinomycin [106], artemisinin, and its derivatives [107-110]. Treatment of cancer-targeting ferroptosis is proved to be solid and bright. Given that ferroptosis also play an important role in CVDs, we can hope that the treatment of CVDs can reach the same extent as cancer soon by regulating ferroptosis.

Given that most CVDs are chronic, pharmacologic modulation of CVDs should be administered for a long time; however, some ferroptosis inhibitors such as deferoxamine are reported to be ototoxic and neurotoxic [103]; therefore, we should focus more on compounds with fewer side effects. Vitamin E, a natural compound, can inhibit ferroptosis by suppressing 15-LOX [101]. Moreover, one study has shown that feeding GPX4 knocking out mice with low vitamin $\mathrm{E}$ food leads to ferroptosis in endothelial cells, which shows that vitamin $\mathrm{E}$ is rather important to protect against ferroptosis [111]. Melatonin, an endogenous antioxidant, is also proved to inhibit ferroptosis induced by hemin, high glucose, traumatic brain injury, and hypoxic-ischemic brain damage [112-115]. These natural materials are safer and can be administered for a long time; however, the curative effect of ferroptosis needs more investigation and may be a hot topic of research in the future.

For a long time, ferroptosis was thought to be regulated only by iron metabolism, lipid peroxidation, and the Xc-GSH-GPX4 pathway; however, recently several novel regulatory pathways were proposed, such as FSP1-CoQ10-NAD(P)H axis, GCH1-BH4-DHFR pathway, and DHODH in mitochondrial. The regulatory pathways are comprehensively depicted in Figure 1. Moreover, NCOA4, Hmox1, BACH1, ACSL4, Nrf2, P53, CoQ10, GCH1 are key molecules in regulating ferroptosis, which were further studied in cardiovascular diseases. For example, in pressure-overloaded heart induced by transverse aortic constriction, NCOA4 was demonstrated to contribute to ventricular dilation, myocardial fibrosis, 
cardiac dysfunction, and hypertrophy, which is related to an increased content of ferrous ion induced by NCOA4-mediated ferritinophagy [116]. As for Hmox1, although it also increases ferrous iron by degrading heme, it exerts obvious protective effects and is a therapeutic target in CVDs, which is closely related to CO production in heme degradation [117]. Therefore, when focusing on the beneficial effects of Hmox1 in CVDs, we should also pay attention to the dark side of inducing ferroptosis. It was demonstrated that CoQ10 is an attractive treatment of CVDs [118-120]; however, we never considered that the mechanism of CoQ10 contains the effect of ferroptosis. Can we target CoQ10 to regulate ferroptosis and further treat CVDs? To what extent is the role of ferroptosis in the treatment of CoQ10? Are there any other downstream regulators of CoQ10 exerting therapeutic effect? In addition, regulatory molecules for ferroptosis such as DHODH and FSP1 have no relationship with CVDs yet; thus, will they become new targets for therapy? All these questions and other novel and effective regulatory mechanisms require further exploration.

Ferroptosis may not be an individual type of cell death. One study shows that the administering of a ferroptosis activator can increase autophagosomes. Moreover, NCOA4mediated ferritinophagy is a kind of autophagy that leads to iron accumulation contributing to ferroptosis [121]. Although ferroptosis is defined as a new kind of cell death that is different from others, the relationship between ferroptosis and other kinds of cell death is vague. How can we regulate those kinds of cell death comprehensively? Whether ferroptosis is an independent type of cell death or just part of other existing types? Are there any other new pathways to regulate ferroptosis?

The existence of ferroptosis was demonstrated in CVDs by most existing studies, even though the research on ferroptosis and CVDs is still in its infancy. In fact, ferroptosis is characterized by redox imbalance and lipid peroxides accumulation, which participate in nearly all the pathogenesis of diseases related to ferroptosis. Therefore, reducing the source of lipid peroxide and increasing its metabolism seem to be the direction of therapy. Highly expressed in cardiomyocytes and catalyzing the formation of ROS, NOX4 are remarkably increased in heart failure. Knocking down TLR4 and NOX4 can remarkably inhibit myocyte death mediated by ferroptosis [12]. Antioxidant puerarin can inhibit lipid oxidation and iron overload in mice with heart failure [13]. As for I/R, ferroptosis inhibitor lip-1 protects heart I/R injury by reducing voltage-dependent anion channel 1 (VDAC1) levels and increasing GPX4 levels [10,11]. Iron homeostasis disturbance is also important to I/R [68]. Nrf2 is a promising target in cardiomyopathy, which is key in modulating antioxidant expression and reducing lipid ROS $[83,84]$. The iron level in healthy arterial tissue is less than that in atherosclerotic plaque [91]. Besides, increasing ox-LDL promotes the development of atherosclerosis. Restricting iron and ox-LDL is thought to be therapeutic for atherosclerosis by inhibiting ferroptosis [54,92]. With ongoing research, the mystery of ferroptosis will be further revealed. Inhibiting ferroptosis is likely to be a promising strategy for CVDs treatment.

Besides the diseases we mentioned above, hypertension, atrial fibrillation, deep vein thrombosis, and aortic aneurysm are critical in CVDs, but few studies illustrated their relationship with ferroptosis [122-125]. Are there any other CVDs that are linked to ferroptosis? How significant is this correlation? Can we prevent other CVDs by targeting ferroptosis? Although the significant role of ferroptosis in CVDs aroused intense scholarly interest and wide attention, all these questions merit further exploration.

Author Contributions: Y.G. and C.L. served as guarantors and contributed equally to literature search, manuscript editing, manuscript preparation, interpretation of data, and study design. K.H. contributed to literature search. W.W. and C.C. contributed to revision and proofreading. All authors contributed to the study conception and design. All authors have read and agreed to the published version of the manuscript.

Funding: This work was supported by the National Natural Science Foundation of China, grant number 81873529 and 82000729 .

Institutional Review Board Statement: Not applicable. 
Informed Consent Statement: Not applicable.

Data Availability Statement: Not applicable.

Acknowledgments: We acknowledge the support of our project team, which includes $\mathrm{Ke} \mathrm{Hu}$, Chuanqi Cai, and Weici Wang, for their helpful and constructive comments that improved the manuscript substantially. Picture was created with biorender.com.

Conflicts of Interest: The authors declare no conflict of interest.

\section{References}

1. Xiao, F.J.; Zhang, D.; Wu, Y.; Jia, Q.H.; Zhang, L.; Li, Y.X.; Yang, Y.F.; Wang, H.; Wu, C.T.; Wang, L.S. miRNA-17-92 protects endothelial cells from erastin-induced ferroptosis through targeting the A20-ACSL4 axis. Biochem. Biophys. Res. Commun. 2019, 515, 448-454. [CrossRef] [PubMed]

2. Wang, Y.; Tang, M. PM2.5 induces ferroptosis in human endothelial cells through iron overload and redox imbalance. Environ. Pollut. 2019, 254, 112937. [CrossRef] [PubMed]

3. Sampilvanjil, A.; Karasawa, T.; Yamada, N.; Komada, T.; Higashi, T.; Baatarjav, C.; Watanabe, S.; Kamata, R.; Ohno, N.; Takahashi, M. Cigarette smoke extract induces ferroptosis in vascular smooth muscle cells. Am. J. Physiol. Heart Circ. Physiol. 2020, 318, H508-H518. [CrossRef]

4. Kapralov, A.A.; Yang, Q.; Dar, H.H.; Tyurina, Y.Y.; Anthonymuthu, T.S.; Kim, R.; St Croix, C.M.; Mikulska-Ruminska, K.; Liu, B.; Shrivastava, I.H.; et al. Redox lipid reprogramming commands susceptibility of macrophages and microglia to ferroptotic death. Nat. Chem. Biol. 2020, 16, 278-290. [CrossRef]

5. $\quad$ Li, Z.; Lin, L.; Wu, H.; Yan, L.; Wang, H.; Yang, H.; Li, H. Global, Regional, and National Death, and Disability-Adjusted Life-Years (DALYs) for Cardiovascular Disease in 2017 and Trends and Risk Analysis From 1990 to 2017 Using the Global Burden of Disease Study and Implications for Prevention. Front. Public Health 2021, 9, 559751. [CrossRef]

6. Roth, G.A.; Johnson, C.; Abajobir, A.; Abd-Allah, F.; Abera, S.F.; Abyu, G.; Ahmed, M.; Aksut, B.; Alam, T.; Alam, K.; et al. Global, Regional, and National Burden of Cardiovascular Diseases for 10 Causes, 1990 to 2015. J. Am. Coll. Cardiol. 2017, 70, 1-25. [CrossRef] [PubMed]

7. Roth, G.A.; Mensah, G.A.; Johnson, C.O.; Addolorato, G.; Ammirati, E.; Baddour, L.M.; Barengo, N.C.; Beaton, A.Z.; Benjamin, E.J.; Benziger, C.P.; et al. Global Burden of Cardiovascular Diseases and Risk Factors, 1990-2019: Update From the GBD 2019 Study. J. Am. Coll. Cardiol. 2020, 76, 2982-3021. [CrossRef]

8. Li, W.; Feng, G.; Gauthier, J.M.; Lokshina, I.; Higashikubo, R.; Evans, S.; Liu, X.; Hassan, A.; Tanaka, S.; Cicka, M.; et al. Ferroptotic cell death and TLR4/Trif signaling initiate neutrophil recruitment after heart transplantation. J. Clin. Investig. 2019, 129, $2293-2304$. [CrossRef]

9. Li, W.; Li, W.; Leng, Y.; Xiong, Y.; Xia, Z. Ferroptosis Is Involved in Diabetes Myocardial Ischemia/Reperfusion Injury through Endoplasmic Reticulum Stress. DNA Cell Biol. 2020, 39, 210-225. [CrossRef]

10. Feng, Y.; Madungwe, N.B.; Imam Aliagan, A.D.; Tombo, N.; Bopassa, J.C. Liproxstatin-1 protects the mouse myocardium against ischemia/reperfusion injury by decreasing VDAC1 levels and restoring GPX4 levels. Biochem. Biophys. Res. Commun. 2019, 520, 606-611. [CrossRef]

11. Dabkowski, E.R.; Williamson, C.L.; Hollander, J.M. Mitochondria-specific transgenic overexpression of phospholipid hydroperoxide glutathione peroxidase (GPx4) attenuates ischemia/reperfusion-associated cardiac dysfunction. Free Rad. Biol. Med. 2008, 45, 855-865. [CrossRef] [PubMed]

12. Chen, X.; Xu, S.; Zhao, C.; Liu, B. Role of TLR4/NADPH oxidase 4 pathway in promoting cell death through autophagy and ferroptosis during heart failure. Biochem. Biophys. Res. Commun. 2019, 516, 37-43. [CrossRef] [PubMed]

13. Liu, B.; Zhao, C.; Li, H.; Chen, X.; Ding, Y.; Xu, S. Puerarin protects against heart failure induced by pressure overload through mitigation of ferroptosis. Biochem. Biophys. Res. Commun. 2018, 497, 233-240. [CrossRef] [PubMed]

14. Conrad, M.; Proneth, B. Broken hearts: Iron overload, ferroptosis and cardiomyopathy. Cell Res. 2019, 29, 263-264. [CrossRef] [PubMed]

15. Fang, X.; Wang, H.; Han, D.; Xie, E.; Yang, X.; Wei, J.; Gu, S.; Gao, F.; Zhu, N.; Yin, X.; et al. Ferroptosis as a target for protection against cardiomyopathy. Proc. Natl. Acad. Sci. USA 2019, 116, 2672-2680. [CrossRef]

16. Bai, T.; Li, M.; Liu, Y.; Qiao, Z.; Wang, Z. Inhibition of ferroptosis alleviates atherosclerosis through attenuating lipid peroxidation and endothelial dysfunction in mouse aortic endothelial cell. Free Rad. Biol. Med. 2020, 160, 92-102. [CrossRef]

17. Dixon, S.J.; Lemberg, K.M.; Lamprecht, M.R.; Skouta, R.; Zaitsev, E.M.; Gleason, C.E.; Patel, D.N.; Bauer, A.J.; Cantley, A.M.; Yang, W.S.; et al. Ferroptosis: An iron-dependent form of nonapoptotic cell death. Cell 2012, 149, 1060-1072. [CrossRef]

18. Agmon, E.; Solon, J.; Bassereau, P.; Stockwell, B.R. Modeling the effects of lipid peroxidation during ferroptosis on membrane properties. Sci. Rep. 2018, 8, 5155. [CrossRef]

19. Hassannia, B.; Vandenabeele, P.; Vanden Berghe, T. Targeting Ferroptosis to Iron Out Cancer. Cancer Cell 2019, 35, 830-849. [CrossRef]

20. Ingold, I.; Berndt, C.; Schmitt, S.; Doll, S.; Poschmann, G.; Buday, K.; Roveri, A.; Peng, X.; Porto Freitas, F.; Seibt, T.; et al. Selenium Utilization by GPX4 Is Required to Prevent Hydroperoxide-Induced Ferroptosis. Cell 2018, 172, 409-422.e421. [CrossRef] 
21. Doll, S.; Freitas, F.P.; Shah, R.; Aldrovandi, M.; da Silva, M.C.; Ingold, I.; Goya Grocin, A.; Xavier da Silva, T.N.; Panzilius, E.; Scheel, C.H.; et al. FSP1 is a glutathione-independent ferroptosis suppressor. Nature 2019, 575, 693-698. [CrossRef] [PubMed]

22. Bersuker, K.; Hendricks, J.M.; Li, Z.; Magtanong, L.; Ford, B.; Tang, P.H.; Roberts, M.A.; Tong, B.; Maimone, T.J.; Zoncu, R.; et al. The CoQ oxidoreductase FSP1 acts parallel to GPX4 to inhibit ferroptosis. Nature 2019, 575, 688-692. [CrossRef]

23. Kraft, V.A.N.; Bezjian, C.T.; Pfeiffer, S.; Ringelstetter, L.; Müller, C.; Zandkarimi, F.; Merl-Pham, J.; Bao, X.; Anastasov, N.; Kössl, J.; et al. GTP Cyclohydrolase 1/Tetrahydrobiopterin Counteract Ferroptosis through Lipid Remodeling. ACS Cent. Sci. 2020, 6, 41-53. [CrossRef] [PubMed]

24. Soula, M.; Weber, R.A.; Zilka, O.; Alwaseem, H.; La, K.; Yen, F.; Molina, H.; Garcia-Bermudez, J.; Pratt, D.A.; Birsoy, K. Metabolic determinants of cancer cell sensitivity to canonical ferroptosis inducers. Nat. Chem. Biol. 2020, 16, 1351-1360. [CrossRef]

25. Garcia-Bermudez, J.; Birsoy, K. A mitochondrial gatekeeper that helps cells escape death by ferroptosis. Nature 2021, 593, 514-515. [CrossRef]

26. Buccarelli, M.; Marconi, M.; Pacioni, S.; De Pascalis, I.; D’Alessandris, Q.G.; Martini, M.; Ascione, B.; Malorni, W.; Larocca, L.M.; Pallini, R.; et al. Inhibition of autophagy increases susceptibility of glioblastoma stem cells to temozolomide by igniting ferroptosis. Cell Death Dis. 2018, 9, 841. [CrossRef] [PubMed]

27. Torii, S.; Shintoku, R.; Kubota, C.; Yaegashi, M.; Torii, R.; Sasaki, M.; Suzuki, T.; Mori, M.; Yoshimoto, Y.; Takeuchi, T.; et al. An essential role for functional lysosomes in ferroptosis of cancer cells. Biochem. J. 2016, 473, 769-777. [CrossRef] [PubMed]

28. Hou, W.; Xie, Y.; Song, X.; Sun, X.; Lotze, M.T.; Zeh, H.J., 3rd; Kang, R.; Tang, D. Autophagy promotes ferroptosis by degradation of ferritin. Autophagy 2016, 12, 1425-1428. [CrossRef]

29. Gao, M.; Monian, P.; Pan, Q.; Zhang, W.; Xiang, J.; Jiang, X. Ferroptosis is an autophagic cell death process. Cell Res. 2016, 26, 1021-1032. [CrossRef]

30. Tang, M.; Chen, Z.; Wu, D.; Chen, L. Ferritinophagy/ferroptosis: Iron-related newcomers in human diseases. J. Cell Physiol. 2018, 233, 9179-9190. [CrossRef]

31. Chang, L.C.; Chiang, S.K.; Chen, S.E.; Yu, Y.L.; Chou, R.H.; Chang, W.C. Heme oxygenase-1 mediates BAY 11-7085 induced ferroptosis. Cancer Lett. 2018, 416, 124-137. [CrossRef] [PubMed]

32. Nishizawa, H.; Matsumoto, M.; Shindo, T.; Saigusa, D.; Kato, H.; Suzuki, K.; Sato, M.; Ishii, Y.; Shimokawa, H.; Igarashi, $\mathrm{K}$. Ferroptosis is controlled by the coordinated transcriptional regulation of glutathione and labile iron metabolism by the transcription factor BACH1. J. Biol. Chem. 2020, 295, 69-82. [CrossRef] [PubMed]

33. Yuan, H.; Li, X.; Zhang, X.; Kang, R.; Tang, D. Identification of ACSL4 as a biomarker and contributor of ferroptosis. Biochem. Biophys. Res. Commun. 2016, 478, 1338-1343. [CrossRef] [PubMed]

34. Li, Y.; Feng, D.; Wang, Z.; Zhao, Y.; Sun, R.; Tian, D.; Liu, D.; Zhang, F.; Ning, S.; Yao, J.; et al. Ischemia-induced ACSL4 activation contributes to ferroptosis-mediated tissue injury in intestinal ischemia/reperfusion. Cell Death Diff. 2019, 26, 2284-2299. [CrossRef]

35. Li, D.; Li, Y. The interaction between ferroptosis and lipid metabolism in cancer. Sign. Transduct. Target. Ther. 2020, 5, 108. [CrossRef]

36. Liu, X.; Zhang, Y.; Zhuang, L.; Olszewski, K.; Gan, B. NADPH debt drives redox bankruptcy: SLC7A11/xCT-mediated cystine uptake as a double-edged sword in cellular redox regulation. Genes Dis. 2021, 8, 731-745. [CrossRef]

37. Xie, Y.; Hou, W.; Song, X.; Yu, Y.; Huang, J.; Sun, X.; Kang, R.; Tang, D. Ferroptosis: Process and function. Cell Death Diff. 2016, 23, 369-379. [CrossRef]

38. Jiang, L.; Kon, N.; Li, T.; Wang, S.J.; Su, T.; Hibshoosh, H.; Baer, R.; Gu, W. Ferroptosis as a p53-mediated activity during tumour suppression. Nature 2015, 520, 57-62. [CrossRef]

39. Tarangelo, A.; Magtanong, L.; Bieging-Rolett, K.T.; Li, Y.; Ye, J.; Attardi, L.D.; Dixon, S.J. p53 Suppresses Metabolic Stress-Induced Ferroptosis in Cancer Cells. Cell Rep. 2018, 22, 569-575. [CrossRef]

40. Song, X.; Long, D. Nrf2 and Ferroptosis: A New Research Direction for Neurodegenerative Diseases. Front Neurosci. 2020, 14, 267. [CrossRef]

41. Fan, Z.; Wirth, A.K.; Chen, D.; Wruck, C.J.; Rauh, M.; Buchfelder, M.; Savaskan, N. Nrf2-Keap1 pathway promotes cell proliferation and diminishes ferroptosis. Oncogenesis 2017, 6, e371. [CrossRef] [PubMed]

42. Kang, Y.P.; Mockabee-Macias, A.; Jiang, C.; Falzone, A.; Prieto-Farigua, N.; Stone, E.; Harris, I.S.; DeNicola, G.M. Non-canonical Glutamate-Cysteine Ligase Activity Protects against Ferroptosis. Cell Metab. 2021, 33, 174-189.e177. [CrossRef] [PubMed]

43. Yang, Y.; Chen, J.; Gao, Q.; Shan, X.; Wang, J.; Lv, Z. Study on the attenuated effect of Ginkgolide B on ferroptosis in high fat diet induced nonalcoholic fatty liver disease. Toxicology 2020, 445, 152599. [CrossRef] [PubMed]

44. Zheng, J.; Conrad, M. The Metabolic Underpinnings of Ferroptosis. Cell Metab. 2020, 32, 920-937. [CrossRef]

45. Dai, E.; Zhang, W.; Cong, D.; Kang, R.; Wang, J.; Tang, D. AIFM2 blocks ferroptosis independent of ubiquinol metabolism. Biochem. Biophys. Res. Commun. 2020, 523, 966-971. [CrossRef]

46. Wang, H.; Liu, C.; Zhao, Y.; Gao, G. Mitochondria regulation in ferroptosis. Eur. J. Cell Biol. 2020, 99, 151058. [CrossRef]

47. DeHart, D.N.; Fang, D.; Heslop, K.; Li, L.; Lemasters, J.J.; Maldonado, E.N. Opening of voltage dependent anion channels promotes reactive oxygen species generation, mitochondrial dysfunction and cell death in cancer cells. Biochem. Pharmacol. 2018, 148, 155-162. [CrossRef]

48. Battaglia, A.M.; Chirillo, R.; Aversa, I.; Sacco, A.; Costanzo, F.; Biamonte, F. Ferroptosis and Cancer: Mitochondria Meet the "Iron Maiden" Cell Death. Cells 2020, 9, 1505. [CrossRef] 
49. Shin, D.; Lee, J.; You, J.H.; Kim, D.; Roh, J.L. Dihydrolipoamide dehydrogenase regulates cystine deprivation-induced ferroptosis in head and neck cancer. Redox Biol. 2020, 30, 101418. [CrossRef]

50. Hardie, D.G.; Schaffer, B.E.; Brunet, A. AMPK: An Energy-Sensing Pathway with Multiple Inputs and Outputs. Trends Cell Biol. 2016, 26, 190-201. [CrossRef]

51. Lee, H.; Zandkarimi, F.; Zhang, Y.; Meena, J.K.; Kim, J.; Zhuang, L.; Tyagi, S.; Ma, L.; Westbrook, T.F.; Steinberg, G.R.; et al. Energy-stress-mediated AMPK activation inhibits ferroptosis. Nat. Cell Biol. 2020, 22, 225-234. [CrossRef] [PubMed]

52. Song, X.; Zhu, S.; Chen, P.; Hou, W.; Wen, Q.; Liu, J.; Xie, Y.; Liu, J.; Klionsky, D.J.; Kroemer, G.; et al. AMPK-Mediated BECN1 Phosphorylation Promotes Ferroptosis by Directly Blocking System X(c)(-) Activity. Curr. Biol. 2018, 28, 2388-2399.e2385. [CrossRef] [PubMed]

53. Zhao, L.; Yang, N.; Song, Y.; Si, H.; Qin, Q.; Guo, Z. Effect of iron overload on endothelial cell calcification and its mechanism. Ann. Translat. Med. 2021, 9, 1658. [CrossRef] [PubMed]

54. Vinchi, F.; Porto, G.; Simmelbauer, A.; Altamura, S.; Passos, S.T.; Garbowski, M.; Silva, A.M.N.; Spaich, S.; Seide, S.E.; Sparla, R.; et al. Atherosclerosis is aggravated by iron overload and ameliorated by dietary and pharmacological iron restriction. Eur. Heart J. 2020, 41, 2681-2695. [CrossRef] [PubMed]

55. Gao, S.; Zhou, L.; Lu, J.; Fang, Y.; Wu, H.; Xu, W.; Pan, Y.; Wang, J.; Wang, X.; Zhang, J.; et al. Cepharanthine Attenuates Early Brain Injury after Subarachnoid Hemorrhage in Mice via Inhibiting 15-Lipoxygenase-1-Mediated Microglia and Endothelial Cell Ferroptosis. Oxidative Med. Cell. Longev. 2022, 2022, 4295208. [CrossRef]

56. Sheng, S.; Xu, J.; Liang, Q.; Hong, L.; Zhang, L. Astragaloside IV Inhibits Bleomycin-Induced Ferroptosis in Human Umbilical Vein Endothelial Cells by Mediating LPC. Oxid. Med. Cell. Longev. 2021, 2021, 6241242. [CrossRef]

57. Ma, W.Q.; Sun, X.J.; Zhu, Y.; Liu, N.F. Metformin attenuates hyperlipidaemia-associated vascular calcification through antiferroptotic effects. Free Rad. Biol. Med. 2021, 165, 229-242. [CrossRef]

58. Hu, X.; Cai, X.; Ma, R.; Fu, W.; Zhang, C.; Du, X. Iron-load exacerbates the severity of atherosclerosis via inducing inflammation and enhancing the glycolysis in macrophages. J. Cell Physiol. 2019, 234, 18792-18800. [CrossRef]

59. Chen, W.; Zuo, F.; Zhang, K.; Xia, T.; Lei, W.; Zhang, Z.; Bao, L.; You, Y. Exosomal MIF Derived From Nasopharyngeal Carcinoma Promotes Metastasis by Repressing Ferroptosis of Macrophages. Front. Cell Develop. Biol. 2021, 9, 791187. [CrossRef]

60. He, R.; Liu, B.; Xiong, R.; Geng, B.; Meng, H.; Lin, W.; Hao, B.; Zhang, L.; Wang, W.; Jiang, W.; et al. Itaconate inhibits ferroptosis of macrophage via Nrf2 pathways against sepsis-induced acute lung injury. Cell Death Discov. 2022, 8, 43. [CrossRef]

61. Ratliff, B.B.; Abdulmahdi, W.; Pawar, R.; Wolin, M.S. Oxidant Mechanisms in Renal Injury and Disease. Antioxid. Redox Sign. 2016, 25, 119-146. [CrossRef] [PubMed]

62. Baba, Y.; Higa, J.K.; Shimada, B.K.; Horiuchi, K.M.; Suhara, T.; Kobayashi, M.; Woo, J.D.; Aoyagi, H.; Marh, K.S.; Kitaoka, H.; et al. Protective effects of the mechanistic target of rapamycin against excess iron and ferroptosis in cardiomyocytes. Am. J. Physiol. Heart Circ. Physiol. 2018, 314, H659-H668. [CrossRef] [PubMed]

63. Fang, X.; Cai, Z.; Wang, H.; Han, D.; Cheng, Q.; Zhang, P.; Gao, F.; Yu, Y.; Song, Z.; Wu, Q.; et al. Loss of Cardiac Ferritin H Facilitates Cardiomyopathy via Slc7a11-Mediated Ferroptosis. Circ. Res. 2020, 127, 486-501. [CrossRef] [PubMed]

64. Ma, S.; Sun, L.; Wu, W.; Wu, J.; Sun, Z.; Ren, J. USP22 Protects Against Myocardial Ischemia-Reperfusion Injury via the SIRT1p53/SLC7A11-Dependent Inhibition of Ferroptosis-Induced Cardiomyocyte Death. Front Physiol. 2020, 11, 551318. [CrossRef] [PubMed]

65. Jacobs, W.; Lammens, M.; Kerckhofs, A.; Voets, E.; Van San, E.; Van Coillie, S.; Peleman, C.; Mergeay, M.; Sirimsi, S.; Matheeussen, V.; et al. Fatal lymphocytic cardiac damage in coronavirus disease 2019 (COVID-19): Autopsy reveals a ferroptosis signature. ESC Heart Fail 2020, 7, 3772-3781. [CrossRef]

66. Su, L.; Jiang, X.; Yang, C.; Zhang, J.; Chen, B.; Li, Y.; Yao, S.; Xie, Q.; Gomez, H.; Murugan, R.; et al. Pannexin 1 mediates ferroptosis that contributes to renal ischemia/reperfusion injury. J. Biol. Chem. 2019, 294, 19395-19404. [CrossRef]

67. Huang, L.L.; Liao, X.H.; Sun, H.; Jiang, X.; Liu, Q.; Zhang, L. Augmenter of liver regeneration protects the kidney from ischaemia-reperfusion injury in ferroptosis. J. Cell Mol. Med. 2019, 23, 4153-4164. [CrossRef]

68. Choi, N.; Whitlock, R.; Klassen, J.; Zappitelli, M.; Arora, R.C.; Rigatto, C.; Ho, J. Early intraoperative iron-binding proteins are associated with acute kidney injury after cardiac surgery. J. Thorac Cardiovasc. Surg. 2019, 157, 287-297.e282. [CrossRef]

69. Lu, J.; Xu, F.; Lu, H. LncRNA PVT1 regulates ferroptosis through miR-214-mediated TFR1 and p53. Life Sci. 2020, $260,118305$. [CrossRef]

70. Friedmann Angeli, J.P.; Schneider, M.; Proneth, B.; Tyurina, Y.Y.; Tyurin, V.A.; Hammond, V.J.; Herbach, N.; Aichler, M.; Walch, A.; Eggenhofer, E.; et al. Inactivation of the ferroptosis regulator Gpx4 triggers acute renal failure in mice. Nat. Cell Biol. 2014, 16, 1180-1191. [CrossRef]

71. Yan, H.F.; Tuo, Q.Z.; Yin, Q.Z.; Lei, P. The pathological role of ferroptosis in ischemia/reperfusion-related injury. Zool Res. 2020, 41, 220-230. [CrossRef] [PubMed]

72. Linkermann, A.; Skouta, R.; Himmerkus, N.; Mulay, S.R.; Dewitz, C.; De Zen, F.; Prokai, A.; Zuchtriegel, G.; Krombach, F.; Welz, P.S.; et al. Synchronized renal tubular cell death involves ferroptosis. Proc. Natl. Acad. Sci. USA 2014, 111, 16836-16841. [CrossRef] [PubMed]

73. Tuo, Q.Z.; Lei, P.; Jackman, K.A.; Li, X.L.; Xiong, H.; Li, X.L.; Liuyang, Z.Y.; Roisman, L.; Zhang, S.T.; Ayton, S.; et al. Tau-mediated iron export prevents ferroptotic damage after ischemic stroke. Mol. Psychiatry 2017, 22, 1520-1530. [CrossRef] [PubMed] 
74. $\quad$ Prass, K.; Ruscher, K.; Karsch, M.; Isaev, N.; Megow, D.; Priller, J.; Scharff, A.; Dirnagl, U.; Meisel, A. Desferrioxamine induces delayed tolerance against cerebral ischemia in vivo and in vitro. J. Cereb. Blood Flow Metab. 2002, 22, 520-525. [CrossRef]

75. Wang, C.; Zhu, L.; Yuan, W.; Sun, L.; Xia, Z.; Zhang, Z.; Yao, W. Diabetes aggravates myocardial ischaemia reperfusion injury via activating Nox2-related programmed cell death in an AMPK-dependent manner. J. Cell. Mol. Med. 2020, 24, 6670-6679. [CrossRef]

76. Gao, M.; Monian, P.; Quadri, N.; Ramasamy, R.; Jiang, X. Glutaminolysis and Transferrin Regulate Ferroptosis. Mol. Cell 2015, 59, 298-308. [CrossRef]

77. Wang, J.; Deng, B.; Liu, Q.; Huang, Y.; Chen, W.; Li, J.; Zhou, Z.; Zhang, L.; Liang, B.; He, J.; et al. Pyroptosis and ferroptosis induced by mixed lineage kinase 3 (MLK3) signaling in cardiomyocytes are essential for myocardial fibrosis in response to pressure overload. Cell Death Dis. 2020, 11, 574. [CrossRef]

78. Ferreira, C.; Bucchini, D.; Martin, M.E.; Levi, S.; Arosio, P.; Grandchamp, B.; Beaumont, C. Early embryonic lethality of H ferritin gene deletion in mice. J. Biol. Chem. 2000, 275, 3021-3024. [CrossRef]

79. Xu, W.; Barrientos, T.; Mao, L.; Rockman, H.A.; Sauve, A.A.; Andrews, N.C. Lethal Cardiomyopathy in Mice Lacking Transferrin Receptor in the Heart. Cell Rep. 2015, 13, 533-545. [CrossRef]

80. Shizukuda, Y.; Matoba, S.; Mian, O.Y.; Nguyen, T.; Hwang, P.M. Targeted disruption of p53 attenuates doxorubicin-induced cardiac toxicity in mice. Mol. Cell Biochem. 2005, 273, 25-32. [CrossRef]

81. Chen, Q.; Thompson, J.; Hu, Y.; Das, A.; Lesnefsky, E.J. Cardiac Specific Knockout of p53 Decreases ER Stress-Induced Mitochondrial Damage. Front. Cardiovasc. Med. 2019, 6, 10. [CrossRef] [PubMed]

82. Tadokoro, T.; Ikeda, M.; Ide, T.; Deguchi, H.; Ikeda, S.; Okabe, K.; Ishikita, A.; Matsushima, S.; Koumura, T.; Yamada, K.I.; et al. Mitochondria-dependent ferroptosis plays a pivotal role in doxorubicin cardiotoxicity. JCI Insight 2020, 5, e132747. [CrossRef]

83. Ge, Z.D.; Lian, Q.; Mao, X.; Xia, Z. Current Status and Challenges of NRF2 as a Potential Therapeutic Target for Diabetic Cardiomyopathy. Int. Heart J. 2019, 60, 512-520. [CrossRef] [PubMed]

84. Abdalkader, M.; Lampinen, R.; Kanninen, K.M.; Malm, T.M.; Liddell, J.R. Targeting Nrf2 to Suppress Ferroptosis and Mitochondrial Dysfunction in Neurodegeneration. Front Neurosci. 2018, 12, 466. [CrossRef] [PubMed]

85. Wang, Y.; Yu, R.; Wu, L.; Yang, G. Hydrogen sulfide guards myoblasts from ferroptosis by inhibiting ALOX12 acetylation. Cell Sign. 2021, 78, 109870. [CrossRef]

86. Kremastinos, D.T.; Farmakis, D. Iron overload cardiomyopathy in clinical practice. Circulation 2011, 124, 2253-2263. [CrossRef]

87. Berdoukas, V.; Coates, T.D.; Cabantchik, Z.I. Iron and oxidative stress in cardiomyopathy in thalassemia. Free Rad. Biol. Med. 2015, 88, 3-9. [CrossRef]

88. Ghanavat, M.; Haybar, H.; Pezeshki, S.M.S.; Shahjahani, M.; Jodat, H.; Elyasi, M.; Saki, N. Cardiomyopathy in Thalassemia: Quick Review from Cellular Aspects to Diagnosis and Current Treatments. Lab. Med. 2020, 51, 143-150. [CrossRef]

89. Mattera, R.; Stone, G.P.; Bahhur, N.; Kuryshev, Y.A. Increased release of arachidonic acid and eicosanoids in iron-overloaded cardiomyocytes. Circulation 2001, 103, 2395-2401. [CrossRef]

90. Lin, M.T.; Beal, M.F. Mitochondrial dysfunction and oxidative stress in neurodegenerative diseases. Nature 2006, 443, 787-795. [CrossRef]

91. Sullivan, J.L. Iron in arterial plaque: Modifiable risk factor for atherosclerosis. Biochim. Biophys. Acta 2009, 1790, 718-723. [CrossRef] [PubMed]

92. Xu, S. Iron and Atherosclerosis: The Link Revisited. Trends Mol. Med. 2019, 25, 659-661. [CrossRef] [PubMed]

93. Martinet, W.; Coornaert, I.; Puylaert, P.; De Meyer, G.R.Y. Macrophage Death as a Pharmacological Target in Atherosclerosis. Front Pharmacol. 2019, 10, 306. [CrossRef] [PubMed]

94. Toyokuni, S.; Yanatori, I.; Kong, Y.; Zheng, H.; Motooka, Y.; Jiang, L. Ferroptosis at the crossroads of infection, aging and cancer Cancer Sci. 2020, 111, 2665-2671. [CrossRef]

95. Lapenna, D.; Ciofani, G.; Pierdomenico, S.D.; Giamberardino, M.A.; Porreca, E. Iron status and oxidative stress in the aged rabbit heart. J. Mol Cell Cardiol. 2018, 114, 328-333. [CrossRef]

96. Cotroneo, E.; Ashek, A.; Wang, L.; Wharton, J.; Dubois, O.; Bozorgi, S.; Busbridge, M.; Alavian, K.N.; Wilkins, M.R.; Zhao, L. Iron homeostasis and pulmonary hypertension: Iron deficiency leads to pulmonary vascular remodeling in the rat. Circ. Res. 2015, 116, 1680-1690. [CrossRef]

97. Naito, Y.; Hosokawa, M.; Sawada, H.; Oboshi, M.; Iwasaku, T.; Okuhara, Y.; Eguchi, A.; Nishimura, K.; Soyama, Y.; Hirotani, S.; et al. Iron is associated with the development of hypoxia-induced pulmonary vascular remodeling in mice. Heart Vess. 2016, 31, 2074-2079. [CrossRef]

98. Ryals, B.; Westbrook, E.; Schacht, J. Morphological evidence of ototoxicity of the iron chelator deferoxamine. Hear Res. 1997, 112, 44-48. [CrossRef]

99. Kang, H.; Han, M.; Xue, J.; Baek, Y.; Chang, J.; Hu, S.; Nam, H.; Jo, M.J.; El Fakhri, G.; Hutchens, M.P.; et al. Renal clearable nanochelators for iron overload therapy. Nat. Commun. 2019, 10, 5134. [CrossRef]

100. Fisher, S.A.; Brunskill, S.J.; Doree, C.; Gooding, S.; Chowdhury, O.; Roberts, D.J. Desferrioxamine mesylate for managing transfusional iron overload in people with transfusion-dependent thalassaemia. Cochrane Database Syst. Rev. 2013, 12, 577-585. [CrossRef]

101. Hinman, A.; Holst, C.R.; Latham, J.C.; Bruegger, J.J.; Ulas, G.; McCusker, K.P.; Amagata, A.; Davis, D.; Hoff, K.G.; Kahn-Kirby, A.H.; et al. Vitamin E hydroquinone is an endogenous regulator of ferroptosis via redox control of 15-lipoxygenase. PLoS ONE 2018, 13, e0201369. [CrossRef] [PubMed] 
102. Liu, Y.; Wang, W.; Li, Y.; Xiao, Y.; Cheng, J.; Jia, J. The 5-Lipoxygenase Inhibitor Zileuton Confers Neuroprotection against Glutamate Oxidative Damage by Inhibiting Ferroptosis. Biol. Pharm. Bull. 2015, 38, 1234-1239. [CrossRef] [PubMed]

103. Hamilton, J.L.; Imran Ul-Haq, M.; Abbina, S.; Kalathottukaren, M.T.; Lai, B.F.; Hatef, A.; Unniappan, S.; Kizhakkedathu, J.N. In vivo efficacy, toxicity and biodistribution of ultra-long circulating desferrioxamine based polymeric iron chelator. Biomaterials 2016, 102, 58-71. [CrossRef] [PubMed]

104. Louandre, C.; Marcq, I.; Bouhlal, H.; Lachaier, E.; Godin, C.; Saidak, Z.; François, C.; Chatelain, D.; Debuysscher, V.; Barbare, J.C.; et al. The retinoblastoma $(\mathrm{Rb})$ protein regulates ferroptosis induced by sorafenib in human hepatocellular carcinoma cells. Cancer Lett. 2015, 356, 971-977. [CrossRef]

105. Sun, X.; Niu, X.; Chen, R.; He, W.; Chen, D.; Kang, R.; Tang, D. Metallothionein-1G facilitates sorafenib resistance through inhibition of ferroptosis. Hepatology 2016, 64, 488-500. [CrossRef]

106. Mai, T.T.; Hamaï, A.; Hienzsch, A.; Cañeque, T.; Müller, S.; Wicinski, J.; Cabaud, O.; Leroy, C.; David, A.; Acevedo, V.; et al Salinomycin kills cancer stem cells by sequestering iron in lysosomes. Nat. Chem. 2017, 9, 1025-1033. [CrossRef]

107. Ooko, E.; Saeed, M.E.; Kadioglu, O.; Sarvi, S.; Colak, M.; Elmasaoudi, K.; Janah, R.; Greten, H.J.; Efferth, T. Artemisinin derivatives induce iron-dependent cell death (ferroptosis) in tumor cells. Phytomedicine 2015, 22, 1045-1054. [CrossRef]

108. Eling, N.; Reuter, L.; Hazin, J.; Hamacher-Brady, A.; Brady, N.R. Identification of artesunate as a specific activator of ferroptosis in pancreatic cancer cells. Oncoscience 2015, 2, 517-532. [CrossRef]

109. Roh, J.L.; Kim, E.H.; Jang, H.; Shin, D. Nrf2 inhibition reverses the resistance of cisplatin-resistant head and neck cancer cells to artesunate-induced ferroptosis. Redox Biol. 2017, 11, 254-262. [CrossRef]

110. Lin, R.; Zhang, Z.; Chen, L.; Zhou, Y.; Zou, P.; Feng, C.; Wang, L.; Liang, G. Dihydroartemisinin (DHA) induces ferroptosis and causes cell cycle arrest in head and neck carcinoma cells. Cancer Lett. 2016, 381, 165-175. [CrossRef]

111. Wortmann, M.; Schneider, M.; Pircher, J.; Hellfritsch, J.; Aichler, M.; Vegi, N.; Kölle, P.; Kuhlencordt, P.; Walch, A.; Pohl, U.; et al Combined deficiency in glutathione peroxidase 4 and vitamin $\mathrm{E}$ causes multiorgan thrombus formation and early death in mice. Circ. Res. 2013, 113, 408-417. [CrossRef] [PubMed]

112. NaveenKumar, S.K.; Hemshekhar, M.; Kemparaju, K.; Girish, K.S. Hemin-induced platelet activation and ferroptosis is mediated through ROS-driven proteasomal activity and inflammasome activation: Protection by Melatonin. Biochim. Biophys. Acta Mol. Basis Dis. 2019, 1865, 2303-2316. [CrossRef] [PubMed]

113. Ma, H.; Wang, X.; Zhang, W.; Li, H.; Zhao, W.; Sun, J.; Yang, M. Melatonin Suppresses Ferroptosis Induced by High Glucose via Activation of the Nrf2/HO-1 Signaling Pathway in Type 2 Diabetic Osteoporosis. Oxid. Med. Cell. Longev. 2020, 2020, 9067610. [CrossRef] [PubMed]

114. Rui, T.; Wang, H.; Li, Q.; Cheng, Y.; Gao, Y.; Fang, X.; Ma, X.; Chen, G.; Gao, C.; Gu, Z.; et al. Deletion of ferritin H in neurons counteracts the protective effect of melatonin against traumatic brain injury-induced ferroptosis. J. Pineal Res. 2021, 70, e12704. [CrossRef] [PubMed]

115. Gou, Z.; Su, X.; Hu, X.; Zhou, Y.; Huang, L.; Fan, Y.; Li, J.; Lu, L. Melatonin improves hypoxic-ischemic brain damage through the Akt/Nrf2/Gpx4 signaling pathway. Brain Res. Bull. 2020, 163, 40-48. [CrossRef]

116. Ito, J.; Omiya, S.; Rusu, M.C.; Ueda, H.; Murakawa, T.; Tanada, Y.; Abe, H.; Nakahara, K.; Asahi, M.; Taneike, M.; et al. Iron derived from autophagy-mediated ferritin degradation induces cardiomyocyte death and heart failure in mice. Elife 2021, 10, e62174. [CrossRef]

117. Otterbein, L.E.; Foresti, R.; Motterlini, R. Heme Oxygenase-1 and Carbon Monoxide in the Heart: The Balancing Act Between Danger Signaling and Pro-Survival. Circ. Res. 2016, 118, 1940-1959. [CrossRef]

118. Sharma, A.; Fonarow, G.C.; Butler, J.; Ezekowitz, J.A.; Felker, G.M. Coenzyme Q10 and Heart Failure: A State-of-the-Art Review. Circ. Heart Fail 2016, 9, e002639. [CrossRef]

119. Suárez-Rivero, J.M.; Pastor-Maldonado, C.J.; de la Mata, M.; Villanueva-Paz, M.; Povea-Cabello, S.; Álvarez-Córdoba, M.; Villalón-García, I.; Suárez-Carrillo, A.; Talaverón-Rey, M.; Munuera, M.; et al. Atherosclerosis and Coenzyme Q(10). Int. J. Mol. Sci. 2019, 20, 5195. [CrossRef]

120. Mortensen, S.A.; Rosenfeldt, F.; Kumar, A.; Dolliner, P.; Filipiak, K.J.; Pella, D.; Alehagen, U.; Steurer, G.; Littarru, G.P. The effect of coenzyme Q10 on morbidity and mortality in chronic heart failure: Results from Q-SYMBIO: A randomized double-blind trial. JACC Heart Fail 2014, 2, 641-649. [CrossRef]

121. Zhou, B.; Liu, J.; Kang, R.; Klionsky, D.J.; Kroemer, G.; Tang, D. Ferroptosis is a type of autophagy-dependent cell death. Semin. Cancer Biol. 2020, 66, 89-100. [CrossRef] [PubMed]

122. Chen, X.; Li, X.; Xu, X.; Li, L.; Liang, N.; Zhang, L.; Lv, J.; Wu, Y.C.; Yin, H. Ferroptosis and cardiovascular disease: Role of free radical-induced lipid peroxidation. Free Radic Res. 2021, 55, 405-415. [CrossRef] [PubMed]

123. Ju, J.; Song, Y.N.; Wang, K. Mechanism of Ferroptosis: A Potential Target for Cardiovascular Diseases Treatment. Aging Dis. 2021, 12, 261-276. [CrossRef] [PubMed]

124. Wu, X.; Li, Y.; Zhang, S.; Zhou, X. Ferroptosis as a novel therapeutic target for cardiovascular disease. Theranostics 2021, 11, 3052-3059. [CrossRef]

125. Li, N.; Jiang, W.; Wang, W.; Xiong, R.; Wu, X.; Geng, Q. Ferroptosis and its emerging roles in cardiovascular diseases. Pharmacol. Res. 2021, 166, 105466. [CrossRef] 